\title{
'Shared listening': using the World Café approach as a revision tool in a final year undergraduate programme
}

\author{
Dr Jackie Farr \\ Faculty of Education and Health, University of Greenwich
}

\section{Introduction}

This case study considers the use and impact of a 'World Café' approach to revising key themes and topics at the end of a $3^{\text {rd }}$ year option course in the BA (Hons) Physical Education and Sport degree at the University of Greenwich. 35 students who undertook an option entitled 'Sport and Disability' in 2011-12 engaged in a 2-hour revision seminar in which the concept of the World Café was introduced, not only as a tool for their own learning, but as a potential method for facilitating discussions and consultations in the workplace, thereby providing an element of vocational application.

\section{World Café}

The World Café approach was initially developed in the early 1990s by Brown who subsequently applied it to a range of settings and produced resources to facilitate the planning and implementation of the method (2002). Wheatley and Brown (in Brown and Isaacs, 2004) called it an 'innovative approach to large group dialogue' and noted the authors' intentions to harvest collective knowledge through discussion and conversation with 'shared listening' (Brown, 2002:12) as an important feature. Shared inquiry is not new however and has many incarnations including for example, 'deliberative discussion', used to enable people and communities to consider solutions to public problems for example (Goodin and Stein, 2008:272). However:

In a World Café dialogue, small, intimate conversations link and build on each other as people move between groups, cross-pollinate ideas and make new connections around questions ...' (Schieffer, Isaacs and Gyllenpalm, 2004:2).

Brown originally set out six 'operating principles' (2002:4) for the format of a World Café although the breadth of each allows flexibility to apply the concept to a range of locations and contexts. Broadly, these seem to divide into aspects of 'hosting' the event, how the space is created (setting, table layouts, refreshments etc) or matters of 'harvesting' and displaying this collective knowledge - 'making collective knowledge visible' (Brown, 2002:4). Whilst, in a community setting, for achieving policy or perhaps strategic outcomes, all six principles are helpful, particularly where people gather from diverse backgrounds (or with diverse experiences) in the context of the university teaching environment, a focus of the management of the 'group rounds' is more likely to be a priority, particularly in a short time period. At the heart of the process however is the notion that it serves to connect diverse ideas and people and encourages contributions from all.

Recently, the World Café approach has transformed into a variety of forms including 'Liquid Café' (from open space technology and liquid worship) and 'the art of hosting'. Whilst World Café is deemed a fairly rigid process by some, other methods are even more informal. In a 
Liquid Café approach for example, unrestricted movement between groups is permitted, unconstrained by time, acknowledging Owen's law of two feet (Owen 1997:98). Owen notes though that this approach may lead to contributors behaving either as 'bumblebees' or 'butterflies':

'Bumblebees move from conversation to conversation, never settling anywhere for long. They 'cross-pollinate' between tables: "Oh, that's interesting. At the table I've just left they were saying..." Butterflies, on the other hand, don't seem to do much at all. They hang around on the periphery, apparently not participating. But they can play a vital role. People come up to them and productive conversations can often ensue.' (Owen, 1997 in Seel, 2006).

\section{Context}

The final year option 'Sport and Disability' is a popular choice for students on the BA (Hons) PE \& Sport programme, who already experience a degree course which includes a considerable element of academic engagement with the concept of 'sports equity'. Students complete a compulsory level 5 module entitled Equity and Diversity in PE and Sport which prepares them for more focused Level 6 study. In 'Sport and Disability', core content considers the application of theoretical models from the broader field of disability studies to the development of sport for disabled people; in particular, the impact of a social/medical model perspective in supporting a critical analysis of disability sport's structures, systems and opportunities. Students learn about issues around representation, empowerment and voice in the context of researching disability. They also hear from outside speakers who can provide insight into either work-based application of the theory, or a more political and contemporary overview of the work of organisations involved in the delivery of competitive sports opportunities for disabled people. In 2011-12, for example, the Chief Executive of ParalympicsGB (formerly the British Paralympic Association) spoke about the issues and controversies of elite disability sport leading up to the bid for hosting the London Games in 2012. Additionally, a focus of the work on researching disability in sport during this course has centred on an emancipatory paradigm (Barnes, 2003 for example) in which athlete's voices are revealed and where disabled sportspeople are empowered through consultation to direct and control their sporting opportunities.

Students undertake 2 assessment items, currently an assignment and an examination with essay-based questions, but also complete 2 critical reviews of the literature which, although not formally assessed, allow them to engage with key texts and journals which support the assessed items and weekly seminar discussions. The World Café revision session, held just before the Easter vacation at the end of March, was intended to 'harvest' (Brown and Isaacs, 2005) and consolidate the key themes to be assessed in the final examination during May.

\section{Method}

The teaching space for this group is normally set up in a traditional (although not always discussion-friendly) way and reflects the university's pooled-room system, whereby a wide range of courses are delivered in spaces which need to 'fit' rapid turn-over of classes in short time periods and with large cohorts. Tables in this particular teaching space were able to be 
moved to suit a cafe scenario but this required access to the room beforehand. Seven key themes or broad discussion topics, based on the taught material and indicative reading, were allocated to groups of chairs and tables with no more than 5 chairs at any one location. Large paper tablecloths were laid out on each set of tables with the key theme printed clearly in the centre and a variety of coloured pens and post-it notes were also provided.

At the start of the session, students were briefed about the purpose of the World Café approach and a set of ground rules (or 'cafe etiquette') was established to facilitate wholegroup discussion. These were drawn from the literature and included an acknowledgement of the right of all to express an opinion, the importance of listening to and sharing information, the role of questioning and the value of doodling, drawing and other visual rather than text-based communication. The tutor also allowed for concerns some students may have with poor handwriting or dyslexia and it was agreed that there would be no comments or corrections made regarding spelling or grammar unless it related to a key text, author, or significant other figure relevant to the discussion theme. Additionally, students were encouraged to note significant issues, themes, authors, language etc on post-it notes and add this to a 'graffiti wall' for discussion at the end of the session.

Brown (2002) recommends spending time constructing the questions asked of each table, but in the context of a course revision exercise, these questions were simple statements of themes covered during the module (e.g. the classification of elite disabled athletes, comparative disability sport, researching disabled sportspeople) on which examination questions would be based.

Students spent 10 minutes at each table in 'circulating focus groups' (Ritch and Brennen, 2010:1), initially annotating the first theme, before rotating to a different table with different students and reading and discussing subsequent themes whilst adding to previous notes made by others. Schieffer et al. (2004:4), identify that leaving behind a 'table host' to brief the incoming guests on the discussion which has just been completed is a useful addition to the process, although this was deemed unworkable during the short space of time for this exercise, where one of the original aims of the exercise was merely collective revision and consolidation of knowledge.

Data were collected through informal observation based on a good understanding of the needs of this cohort developed over a 3 year period. Further, this option has been delivered by one tutor for 2 hours a week over the previous 18 weeks and, therefore a claim can be made by the researcher for a degree of familiarity with collective and individual knowledge and understanding.

\section{Results}

This was by no means a rigorous study and no claims are made for the outcomes in research terms; it is merely a semi-anecdotal sharing of practice which appeared to have some value for a group of students with a range of needs. Observations were made over the 2-hour period and notes taken by the tutor as she circulated. Students engaged fully in the concept and many found strengths in topic areas which they had not previously considered important or of interest. For several, it appeared that the technique highlighted 
lack of attendance or engagement with the reading or seminar tasks over the previous weeks, although this arose in a fairly private and non-threatening way and served to indicate to individual students the importance of revisiting some of the taught session content. Students also found that there were recurring themes, which were of a theoretical or philosophical nature, which could be applied to the broad topic areas and further discussion revealed the exact nature of a 'theoretical underpinning' to critical analysis, a concept which many students had previously found difficult to grasp.

From a practical point of view, some topics became saturated (Bowen, 2008) fairly quickly but this was helpful in that it allowed further reflection and even careful editing. Students were encouraged to ask for clarification of points made by others through the plenary discussion, or to annotate the paper with question marks which were then considered as a whole group. Rotating round tables allowed all students to consider all topics and to work with people they would not usually engage in discussion with beyond semi-structured seminars as part of the course. This free-flow of ideas was productive and it appeared, from observation, to be a relaxing and non-threatening environment. Students with dyslexia $(10 \%$ of the group) reported that the technique worked particularly well for them.

The 'graffiti wall', whilst not a feature of Brown's original work, produced some observations which were mostly related to the jargon of the topic ('hegemonic male discourse of disability', 'emancipatory paradigm' for example) as well as key authors which students shared with each other and were able to recommend to the group in the final discussion (e.g. Mike Oliver, Hayley Fitzgerald). One student had simply put the date '1995' on a post-it and almost all the group were able to identify this as a pivotal year for disabled people in British society with the passing of the Disability Discrimination Act (DDA).

The technique allowed for almost immediate feedback and generated much discussion. Students were able to photograph the final papers and the use of the department's iPads (provided through EDU project funding) to capture the images allowed this information to be uploaded to Moodle for further reference.

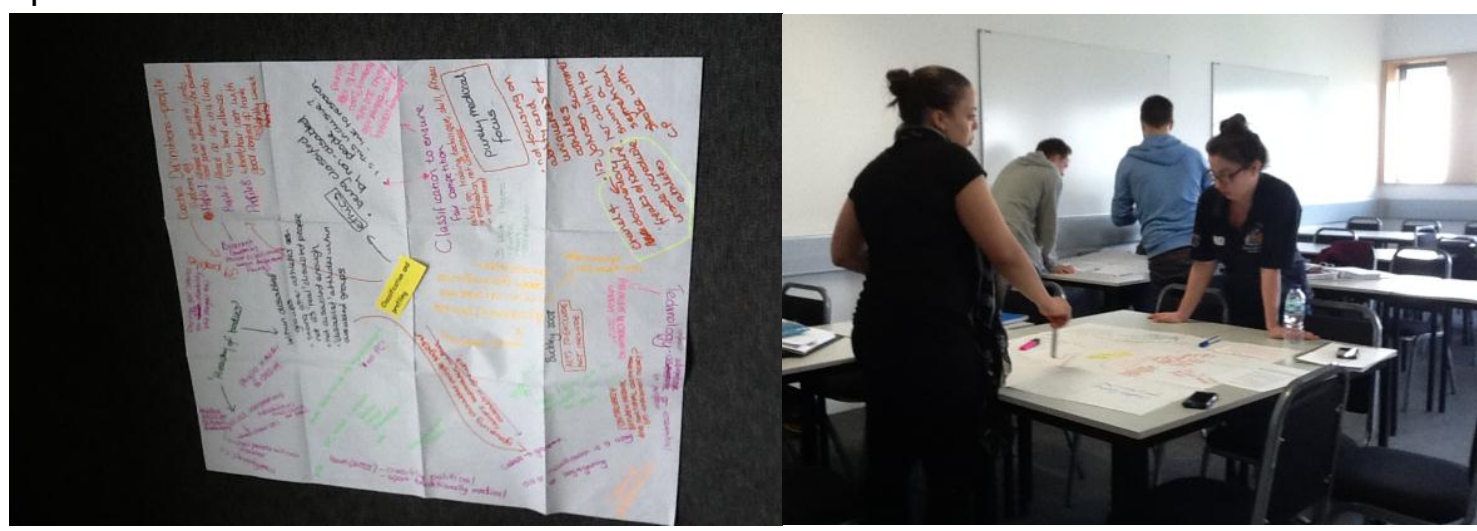

\section{Limitations}

This activity, when used for revision purpose, relies heavily on secure knowledge in the first instance and therefore perhaps requires closer 'hosting' than when used in other settings. Students' over-confidence but sketchy knowledge in some areas meant that occasionally there was an effect similar to the children's game, Broken Telephone, whereby one person had written something which was later elaborated on by other groups resulting in an 
inaccurate perception. Schieffer et al. (2004) acknowledged this as an 'unfortunate human tendency'. Additionally, where students had not written or animated their ideas clearly, it resulted in occasional misunderstanding by subsequent groups.

These are important observations: the tutor (or 'host') has a responsibility to facilitate the feedback and to make their own annotations or clarify key comments in order to ensure accuracy where necessary. This would not be the case in the context of the use of this tool in a purely consultative manner in, for example, a local community sports setting where the validity and integrity of the experience is important and a distinct lack of regulation or interference by the host would be a strength.

\section{Conclusion}

There were two main outcomes of adopting the World Café approach in the context of this module: academic and vocational. Firstly, to begin the course revision process through shared knowledge and consolidation. Secondly, to explore a method which has application in a workplace which, for most students graduating from this programme, is usually schoolbased (the majority train as teachers) or finds them progressing to Local Authority or National Governing Body of Sport development or coaching roles.

The management of the academic outcomes requires considerable and constant monitoring with formative feedback and solid subject knowledge on the part of the café host. Whilst conversations can be generated which allow a degree of freedom on the part of the student, care is needed to manage misconceptions and inaccuracies. Reflecting on this allowed the host (the course tutor) to consider where, during the taught elements of the course, certain items could have been further developed, more clearly explained or equally, be given less prominence. Whilst the café approach might appear to be a liberating experience for students, there remains an argument about the nature of assessment and the drive to ensure students are fully supported and prepared for final examinations. Additionally, the value of World Café over perhaps, Liquid Café as a process for revision appears stronger given the potential of Owen's butterfly effect.

In vocational terms, creating, shaping, funding and managing sports opportunities for disabled people requires innovative approaches to consultation which, it can be argued, is a visible outcome of the World Café. In an emancipatory paradigm, the voice of the 'researched' is deemed important; consultation plays a pivotal part in shaping opportunities and in leadership and empowerment. A World Café approach, when applied to a consultation scenario in a range of professional settings, has value in terms of the richness and depth of items which can be raised from a clear, focused initial question or statement. The freedom to voice concerns and share knowledge, particularly where the discussion topic is something the participants are passionate about, is powerful in the context of working with a traditionally disenfranchised group of people in sport. Assuming students have the same passion for learning:

'There is nothing more powerful than a community engaged in conversation in relation to what it cares about' (Brown, 2002:16). 
Having conducted this exercise at the end of the 2012 academic year, it was repeated for a different cohort of final year students $(n=26)$ on the same course completing in March 2013 with very similar effects and feedback. The resulting summer exam performances were undeniably strong with $92 \%$ of students $(n=24)$ passing outright (unsuccessful students were those who had not attended). More importantly, the number of students gaining grades in the $1^{\text {st }}$ or 2:1 category, indicating a level of critical rather than superficial or descriptive engagement with the work was pleasingly high at $58 \%(n=15)$. Whilst this cannot be directly attributed to the World Café method which supported their revision, it certainly did the students no harm, was possibly helpful in boosting confidence and it would therefore be safe to assume that the method is worth retaining as part of a toolbox for lecturers keen to support their students to be successful in an exam context.

\section{References}

Barnes, C. (2003) What a difference a decade makes: reflections on doing 'emancipatory' disability research. Disability \& Society, Vol.18, Issue 1, pp3-17.

Bowen, G.A. (2008) Naturalistic Enquiry and the saturation concept: a research note. Qualitative Research, Vol. 8, pp. 137-152.

Brown, J. (2002) The World Café, A Resource Guide for Hosting Conversations that Matter. Mill Valley, CA: Whole Systems Associates.

Brown, J. and Isaacs, D. (2004) What is a 'World Café'? Future of Work Agenda. The Work Design Collaborative LLC.

Brown, J. and Isaacs, D. (2005) The World Café: Shaping our futures through conversations that matter. San Francisco: Berrett-Koehler.

Goodin, H.J. and Stein, D. (2008) Deliberative discussion as an innovative teaching strategy. Journal of Nursing Education, Vol. 47, No. 6 pp 272-4.

Owen, H. (1997) Open Space Technology: A User's Guide. San Francisco: Berrett-Koehler.

Ritch, E.L. and Brennen, C. (2010) Using World Café and drama to explore older people's experience of financial products and services. International Journal of Consumer Studies. Vol. 34, Issue 4, pp 405-411.

Schieffer, A., Isaacs, D. and Gyllenpalm, B. (2004) The World Café. World Business Academy, Transformation. Vol. 18, Issue 8.

Seel, R. (2006) Liquid Café. [Online]. Available at: http://www.newparadigm.co.uk/liquid_cafe.htm. (Accessed 5th July 2013).

\section{Author Biography}

Dr Jackie Farr taught Physical Education (PE) in mainstream secondary schools in Kent before moving into special education as a residential Head of PE in a school for children with physical disabilities and complex medical needs. She moved from teaching to sports development, holding county and regional management posts in disability sport and was a member of the coaching staff of the Great Britain Paralympic swim team. 
Dr Farr has published training materials on inclusion in sport and PE and worked as an equity trainer for Sport England. Additionally, she has acted as a lead trainer to a number of governing bodies of sport in their development of both child protection in sport and equity policies. Within the University of Greenwich, she is responsible for the teaching of swimming practical areas and co-ordinates undergraduate courses in sports policy and practice, sports development, sports equity and sport and disability. 